\title{
Pressure dependence of the deuterium isotope effect in the photolysis of formaldehyde by ultraviolet light
}

\author{
E. J. K. Nilsson ${ }^{1}$, V. F. Andersen ${ }^{1}$, H. Skov ${ }^{2}$, and M. S. Johnson ${ }^{1}$ \\ ${ }^{1}$ Copenhagen Center for Atmospheric Research, Department of Chemistry, University of Copenhagen, Universitetsparken 5, \\ Copenhagen, Denmark \\ ${ }^{2}$ National Environmental Research Institute, Department of Atmospheric Environment, University of Aarhus, Denmark
}

Received: 9 October 2009 - Published in Atmos. Chem. Phys. Discuss.: 12 November 2009

Revised: 20 March 2010 - Accepted: 1 April 2010 - Published: 14 April 2010

\begin{abstract}
The pressure dependence of the relative photolysis rate of HCHO vs. HCDO has been investigated for the first time, using a photochemical reactor at the University of Copenhagen. The dissociation of HCHO vs. HCDO using a UVA lamp was measured at total bath gas pressures of 50 , 200, 400, 600 and 1030 mbar. The products of formaldehyde photodissociation are either $\mathrm{H}_{2}+\mathrm{CO}$ (molecular channel) or $\mathrm{HCO}+\mathrm{H}$ (radical channel), and a photolysis lamp was chosen to emit light at wavelengths that greatly favor the molecular channel. The isotope effect in the dissociation, $k_{\mathrm{HCHO}} / k_{\mathrm{HCDO}}$, was found to depend strongly on pressure, varying from $1.1+0.15 /-0.1$ at $50 \mathrm{mbar}$ to $1.75 \pm 0.10$ at $1030 \mathrm{mbar}$. The results can be corrected for radical channel contribution to yield the kinetic isotope effect for the molecular channel; i.e. the KIE in the production of molecular hydrogen. This is done and the results at 1030 mbar are discussed in relation to previous studies at ambient pressure. In the atmosphere the relative importance of the two product channels changes with altitude as a result of changes in pressure and actinic flux. The study demonstrates that the $\delta \mathrm{D}$ of photochemical hydrogen produced from formaldehyde will increase substantially as pressure decreases.
\end{abstract}

\section{Introduction}

Formaldehyde, $\mathrm{HCHO}$, is a key intermediate in the atmospheric carbon cycle and is important to the atmosphere's oxidative capacity. $\mathrm{HCHO}$ is a product of the oxidation of methane and virtually all non-methane hydrocarbons, and is a precursor of atmospheric $\mathrm{CO}$ and $\mathrm{H}_{2}$. Over half of atmo-

Correspondence to: M. S. Johnson (msj@kiku.dk) spheric $\mathrm{H}_{2}$ is produced from the photolysis of formaldehyde (Ehhalt and Rohrer, 2009; Novelli et al., 1999; Rhee et al., 2006a). Molecular hydrogen is the reduced gas in the atmosphere with the largest turnover in moles and acts as an indirect greenhouse gas (Forster et al., 2007). The reaction with $\mathrm{OH}$ removes ca. $20 \%$ of $\mathrm{H}_{2}$, while $80 \%$ is removed by a soil sink (Rhee et al., 2006b). There is an interest in the fate of molecular hydrogen in the atmosphere, in order to understand the environmental impact of a proposed hydrogen economy (Rahn et al., 2003).

Inverse modeling of the deuterium budget of tropospheric hydrogen provides an independent check of bottom-up budgets relying on estimates of individual source and sink terms (Ehhalt and Rohrer, 2009). Gerst and Quay's analysis of the isotope budget concludes that the photochemical source of $\mathrm{H}_{2}$ must be highly enriched in deuterium (Gerst and Quay, 2001). They estimate that photochemical $\mathrm{H}_{2}$ should have a $\delta \mathrm{D}$ of $+130 \pm 70 \%$ o compared to ocean water, a significant enrichment relative to the dominant source, methane, with a $\delta \mathrm{D}$ of $-86 \pm 3 \%$. According to Schmidt et al. (2003) biogenic VOC is likely to be at least this depleted in deuterium. Measurements show that tropospheric hydrogen has a $\delta \mathrm{D}$ of $120 \%$. The $\delta \mathrm{D}$ value for stratospheric hydrogen ranges from close to the tropospheric value to above $400 \%$ in the upper stratosphere; a substantial enrichment must take place (Rahn et al., 2003; Röckmann et al., 2003). In their efforts to model observed $\delta \mathrm{D}$ values both Mar et al. and Röckmann et al. $(2003,2007)$ varied the fractionation factor in the photolytic molecular hydrogen source (Mar et al., 2007; Röckmann et al., 2003). In addition Mar et al. investigated a number of factors that could result in variation with altitude and conclude that while there appears to be such a variation it cannot be known with certainty due to the lack of experimental evidence.

Published by Copernicus Publications on behalf of the European Geosciences Union. 
Table 1. Summary of previous experimental result, and the results obtained at 1030 mbar in this study.

\begin{tabular}{llllll}
\hline Experimental facility and volume & Light source & $\begin{array}{l}k_{\mathrm{HCHO}} / k_{\mathrm{HCDO}} \\
\text { Total }\end{array}$ & Molecular & Radical & Reference \\
\hline EUPHORE, $200 \mathrm{~m}^{3}$ chamber & Sunlight & $1.58 \pm 0.03$ & $1.82 \pm 0.07$ & $1.1 \pm 0.06$ & Feilberg et al., 2007 \\
Glass/quartz vessel, 1-31 & Sunlight & $2.5 \pm 0.03$ & $2.0 \pm 0.02$ & $4.5 \pm 0.08$ & Rhee et al., 2008 \\
SAPHIRE, $370 \mathrm{~m}^{3}$ chamber & Sunlight & $1.63 \pm 0.03$ & $1.63 \pm 0.03$ & & Röckmann et al., 2009 \\
Quartz chamber, 1011 & UVA & $1.75 \pm 0.1$ & & This work \\
\hline
\end{tabular}

Establishing the kinetic isotope effects involved in the atmospheric oxidation of methane and non-methane volatile organic carbon species is important due to ongoing interest in modeling the molecular hydrogen and hydrocarbon budgets, (see for example Ehhalt and Rohrer, 2009; Feilberg et al., 2007; Pieterse et al., 2009). The C-D bond in methane is less reactive than the $\mathrm{C}-\mathrm{H}$ bonds and when methane is oxidized this results in methoxy radicals that are enriched in deuterium. Furthermore, a recent study showed that there is a large deuterium enrichment in the formaldehyde produced by the reaction of the methoxy radical with oxygen (Nilsson et al., 2007):

$$
\begin{aligned}
\mathrm{CH}_{2} \mathrm{DO}+\mathrm{O}_{2} & \rightarrow \mathrm{HCDO}+\mathrm{HO}_{2}(88.2 \pm 1.1 \%) \\
& \rightarrow \mathrm{HCHO}+\mathrm{DO}_{2}(11.8 \pm 1.1 \%)
\end{aligned}
$$

The enrichment of deuterium in the initial steps of monodeutero methane oxidation is only partially counteracted by the deuterium depletion seen in the hydrogen produced from photolysis of formaldehyde (Feilberg et al., 2007).

The photolysis of formaldehyde has two product channels, the radical channel producing $\mathrm{H}$ and $\mathrm{HCO}$ and the molecular channel producing $\mathrm{H}_{2}$ and $\mathrm{CO}$.

$$
\begin{aligned}
& \mathrm{HCHO}+\mathrm{h} v \rightarrow \mathrm{HCO}+\mathrm{H} \text { Radical channel } \\
& \mathrm{HCHO}+\mathrm{h} v \rightarrow \mathrm{H}_{2}+\mathrm{CO} \text { Molecular channel }
\end{aligned}
$$

The molecular channel includes a contribution from:

$\mathrm{HCHO}+\mathrm{h} v \rightarrow \mathrm{H} \cdot \mathrm{HCO} \rightarrow \mathrm{H}_{2}+\mathrm{CO}$ "Roaming atom"

The threshold energy for Reaction (R3) corresponds to a wavelength of about $330 \mathrm{~nm}$, possibly extending as far as $340 \mathrm{~nm}$. The production of $\mathrm{H}_{2}$ and $\mathrm{CO}$ via Reaction (R4) has a threshold energy of ca. $360 \mathrm{~nm}$ (Troe, 2007). In addition a fraction of the radical dissociations produce molecular products via the "roaming atom" pathway Reaction (R5) (Bowman and Zhang, 2006; Townsend et al., 2004). The photolysis of formaldehyde is associated with significant deuterium, ${ }^{13} \mathrm{C}$ and ${ }^{18} \mathrm{O}$ isotope effects (Feilberg et al., 2005; Feilberg et al., 2007; Gratien et al., 2007; Jørgensen et al. 2008)

Quantum yields for the two product channels have been evaluated and parameterized by Sander et al. (2006). While the pressure dependence of the molecular channel quantum

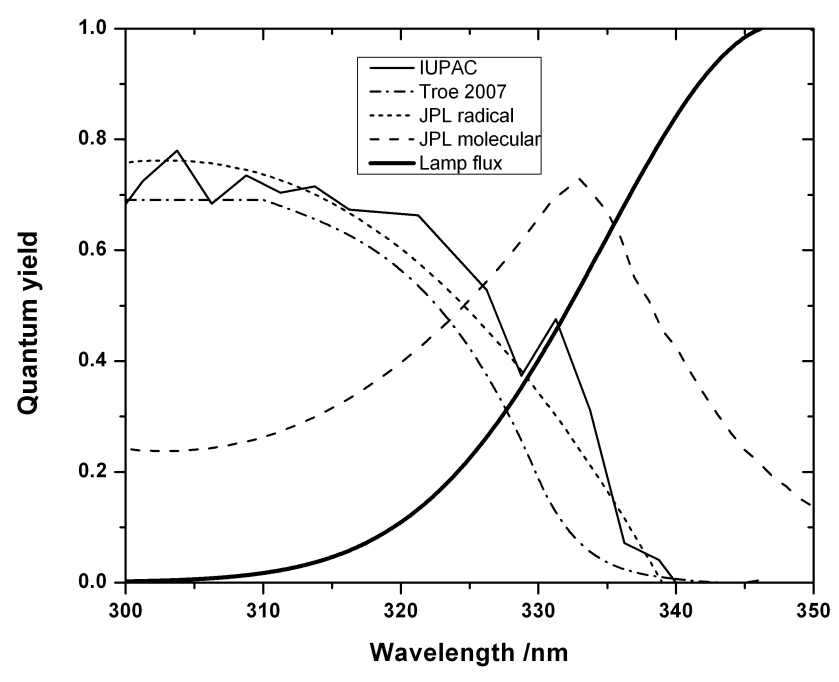

Fig. 1. Pressure independent quantum yields of radical products of formaldehyde photolysis as a function of wavelength from JPL (Sander et al., 2006), IUPAC (Atkinson et al., 2005), and the lowest estimate by Troe (Troe, 2007). The JPL quantum yield in the molecular channel, for a pressure of $1 \mathrm{~atm}$, is included for comparison. Thicker full drawn line is the emission spectrum of the UV-A lamp (Osram Eversun 100W/79) used for the photolysis experiments.

yield is significant, no pressure dependence is observed in the radical channel. The quantum yield recommended by JPL (Sander et al., 2006) is a parameterization based on diverse experimental data. In contrast, IUPAC recommends a more structured quantum yield (Atkinson et al., 2005). A theoretical paper by Troe discusses the possibility that the radical channel quantum yield is lower at higher wavelengths (330$340 \mathrm{~nm}$ ) than the current recommendations (Troe, 2007). The IUPAC, JPL and Troe quantum yields for the radical channel and the yield in the molecular channel at 1030 mbar total pressure are shown in Fig. 1. The group of Orr-Ewing also reports a more structured quantum yield that is higher for the radical channel than previous results (Gorrotxategi Carbajo et al., 2008).

Table 1 summarizes the available experimental results at ambient conditions for the isotope effects in the photolysis of formaldehyde. Previous studies have been conducted under ambient conditions using natural sunlight; the present study 
is the first one where the pressure dependence in the isotope effect is investigated. The different results for the deuterium KIE in the overall rate, and in the molecular and radical channels, will be discussed in Sect. 4 below.

Pieterse et al. (2009) have used a model to investigate the oxidation process from methane to molecular hydrogen (Pieterse et al., 2009). They identify the isotope effects in formaldehyde photolysis as "by far the most critical parameters in the $\mathrm{H}_{2}$ isotope scheme".

We have undertaken the present study to investigate the effect of pressure on the kinetic isotope effect in formaldehyde photodissociation. Since pressure dependence is only expected in the molecular channel, a photolysis lamp was used that mainly dissociates formaldehyde in this channel. Using the experimentally determined $k_{\mathrm{HCHO}} / k_{\mathrm{HCDO}}$ together with literature data on the channel-specific quantum yields, we estimate the magnitude of the isotope effects in the molecular channel.

\section{Experimental}

\subsection{Experimental setup}

The photolysis experiments were carried out in a photochemical reactor at the University of Copenhagen (Nilsson et al., 2009). The reaction chamber is a $2 \mathrm{~m}$ quartz tube with electropolished stainless steel end flanges and a volume of 101.41. The chamber is placed in an insulated, temperature controlled housing. The output beam from a Bruker IFS66v/s FTIR spectrometer is coupled to the White type optics of the reaction chamber and used to monitor changes in reactant concentrations. The absorption path length in the cell was $72 \mathrm{~m}$ and a liquid nitrogen cooled InSb detector was used. Pressures were determined using temperature stabilized capacitance manometer gauges accurate to $0.125 \%$. The experimental setup is described in detail in Nilsson et al. (2009).

\subsection{Photolysis of $\mathrm{HCHO} / \mathrm{HCDO}$}

The two formaldehyde isotopologues in the form of paraformaldehyde were carefully heated and introduced into the chamber via a heated inlet, in order to avoid condensation of formaldehyde in the inlet line exposed to the possibly colder laboratory air. The initial amount of formaldehyde was determined by measuring the pressure in a calibrated volume before the gas was expanded into the chamber. The chamber was then filled to the target pressure with synthetic air. Experiments were conducted at a variety of $\mathrm{HCHO}$ to HCDO ratios and concentrations. Initial partial pressures of HCHO and HCDO in each experiment are listed in Table 2. Total pressures in the cell were 50, 200, 400, 600 and $1030 \mathrm{mbar}$, and the temperature was $293 \pm 0.5 \mathrm{~K}$ in all experiments. Photolysis was performed in 8 to 20 steps of increasing duration giving a total photolysis time of 6 to $35 \mathrm{~h}$, using 8 UV-A lamps. The lamps used have the emission maximum
Table 2. Summary of experimental results at different chamber pressures. The second column presents the isotope effect $k_{\mathrm{HCHO}} / k_{\mathrm{HCDO}}$ obtained from the relative rate plots. The last column gives the initial partial pressures of the two isotopologues in each experiment.

\begin{tabular}{lll}
\hline $\begin{array}{l}\text { Chamber } \\
\text { pressure }(\mathrm{mbar})\end{array}$ & $k_{\mathrm{HCHO}} / k_{\mathrm{HCDO}}$ & $\mathrm{HCHO} / \mathrm{HCDO}(\mu \mathrm{bar})$ \\
\hline 50 & $1.064 \pm 0.039$ & $0.68 / 0.03$ \\
50 & $1.207 \pm 0.040$ & $0.55 / 0.22$ \\
50 & $1.058 \pm 0.032$ & $0.17 / 0.38$ \\
50 & $1.076 \pm 0.036$ & $0.08 / 0.38$ \\
200 & $1.357 \pm 0.080$ & $0.029 / 0.005$ \\
200 & $1.205 \pm 0.037$ & $0.67 / 0.03$ \\
200 & $1.354 \pm 0.041$ & $0.053 / 0.034$ \\
400 & $1.621 \pm 0.056$ & $0.20 / 0.18$ \\
400 & $1.629 \pm 0.052$ & $0.46 / 0.30$ \\
600 & $1.792 \pm 0.055$ & $0.15 / 0.23$ \\
600 & $1.718 \pm 0.069$ & $0.27 / 0.07$ \\
1030 & $1.784 \pm 0.055$ & $1.13 / 0.08$ \\
1030 & $1.718 \pm 0.069$ & $4.2 / 0.3$ \\
1030 & $1.792 \pm 0.054$ & $0.21 / 0.19$ \\
\hline
\end{tabular}

at $350 \mathrm{~nm}$, for spectral distribution in the relevant range see Fig. 1.

\subsection{Reference spectra and analysis of FTIR data}

FTIR spectra were analyzed using a spectral fitting program that generates a synthetic spectrum which is compared to the experimental result (Griffith, 1996). The program uses either high quality line parameters from the HITRAN data base (Rothman et al., 2005) or high resolution reference spectra.

For spectra taken at total pressures of 400, 600 and 1030 mbar, the absorption cross sections published by Gratien et al. (2007) were used as reference spectra. Spectra recorded at 50 and $200 \mathrm{mbar}$ were analyzed using high resolution reference spectra obtained with a Bruker HR-120 FTIR spectrometer. Three spectra were recorded for each isotopologue, at a resolution of $0.05 \mathrm{~cm}^{-1}$, each spectrum consisting of 64 co-added interferograms. The three spectra were averaged to obtain the final spectrum used for the analysis.

The natural logarithm of the relative concentrations of the two species HCHO and HCDO were plotted for each experiment. The slope of the line in these plots, known as relative rate plots, gives the ratio of the photolysis rates.

\section{Results and discussion}

We take $j$ as the rate of photoabsorption, and distinguish this from the rate of photodissociation $k$, which can be further divided into radical and molecular channel dissociation, 


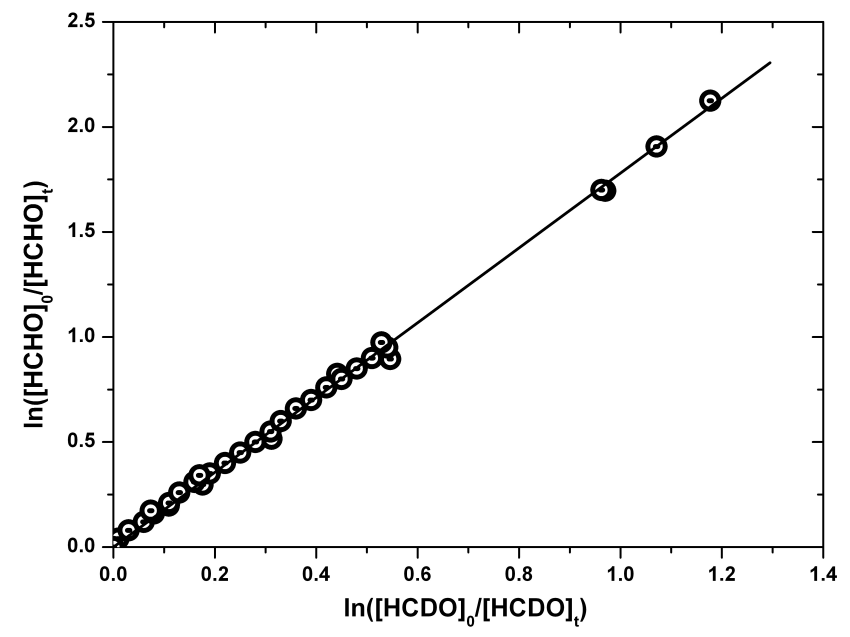

Fig. 2. Relative rate plots of $\mathrm{HCHO}$ versus HCDO from three independent experiments at $293 \mathrm{~K}$ and total pressure of 1030 mbar, error bars within symbols.

mboxdefined in Eq. (1) below, plus the rate of collisional quenching. Figure 2 shows an example of a relative rate plot where the slope is $k_{\mathrm{HCHO}} / k_{\mathrm{HCDO}}$, the ratio of the rates of photodissociation of the two species. This plot includes data from three independent experiments conducted at $1030 \mathrm{mbar}$ total pressure and $293 \pm 0.5 \mathrm{~K}$. Similar plots were constructed at each pressure. The isotope effects determined in each experiment are summarized in column 2 of Table 2. The results are also plotted in Fig. 3, where a significant pressure dependence is clearly seen. Error bars are based on the uncertainty in the determination of the slope of the relative rate plot with an additional 3\% error to account for possible uncertainties in reference spectra. At the lowest pressure, $50 \mathrm{mbar}, k_{\mathrm{HCHO}} / k_{\mathrm{HCDO}}$ is determined in four experiments, three of them giving results that (including error bars) span the range 1.03-1.12 while one is an outlier with a value above 1.2. It is also interesting to note that $k_{\mathrm{HCHO}} / k_{\mathrm{HCDO}}$ at 600 and $1030 \mathrm{mbar}$ are indistinguishable; there seems to be a threshold pressure above which further increase in pressure does not affect the isotope effect.

There are five possible loss pathways for formaldehyde in the experiments: photolysis into either the molecular or the radical channel, reaction with $\mathrm{OH}$ or $\mathrm{HO}_{2}$, and loss of formaldehyde to the walls. To investigate the wall loss rate, control experiments were performed in which the lamps were not switched on. The concentration of formaldehyde in the chamber was monitored for several hours to check for changes in concentration and isotopic composition. It was seen that the amount of formaldehyde decreased by at most a few percent, stabilizing after about half an hour. This is interpreted as loss of formaldehyde to the walls. No change in the isotopic composition of the gas phase formaldehyde was seen; the affinities for the walls are apparently the same for $\mathrm{HCHO}$ and HCDO.

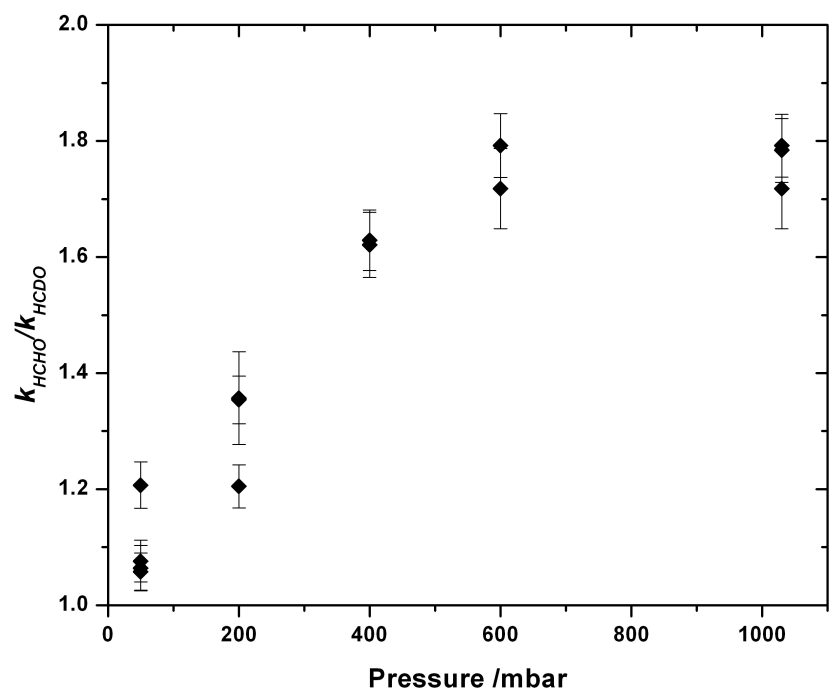

Fig. 3. Relative dissociation rate of formaldehyde, $k_{\mathrm{HCHO}} / k_{\mathrm{HCDO}}$, as a function of pressure. The same data are as presented in Table 2. Error bars are based on the uncertainty in the determination of the slope of the relative rate plot with an additional $3 \%$ error to account for possible uncertainties in reference spectra.

Possible loss of formaldehyde by reaction with $\mathrm{OH}$ and $\mathrm{HO}_{2}$ during the photolysis experiments was investigated using a kinetic model written using Kintecus (Ianni, 2005), available as Supplementary Information (http://www.atmos-chem-phys.net/10/3455/2010/ acp-10-3455-2010-supplement.pdf). Initial concentrations of $\mathrm{HCHO}, \mathrm{HCDO}, \mathrm{H}_{2} \mathrm{O}$ and $\mathrm{CO}$ determined from the experiments using FTIR spectroscopy were used as input for the model. In the model run, less than $1 \%$ of the formaldehyde was lost by reaction with $\mathrm{OH}$, and less than $1 \%$ via reaction with $\mathrm{HO}_{2}$.

The kinetic isotope effects presented this far are based on the loss of formaldehyde and do not distinguish between the product channels. The lamp emission spectrum and quantum yields in Fig. 1 show that while most of the products will be from the molecular channel, the contribution from the radical channel is not negligible. The relative importance of the two product channels can be estimated using Eq. (1) where the subscript $i$ distinguishes the radical channel (1) from the molecular channel (2).

$k_{i}=\int \sigma(\lambda) \phi_{i}(\lambda) I(\lambda) d \lambda$

The absorption cross section, $\sigma(\lambda)$, has recently been determined with high accuracy by Gratien et al. (2007). $I(\lambda)$ is the emission spectra of the photolysis lamps. Quantum yields for the molecular channel, $\phi(\lambda)$, are, as mentioned, pressure dependent; due to collisional quenching the rate of absorption is larger than the rate of dissociation. The pressure dependence is shown in Fig. 4 by a plot of $\phi(\lambda) I(\lambda)$ vs. wavelength, for 


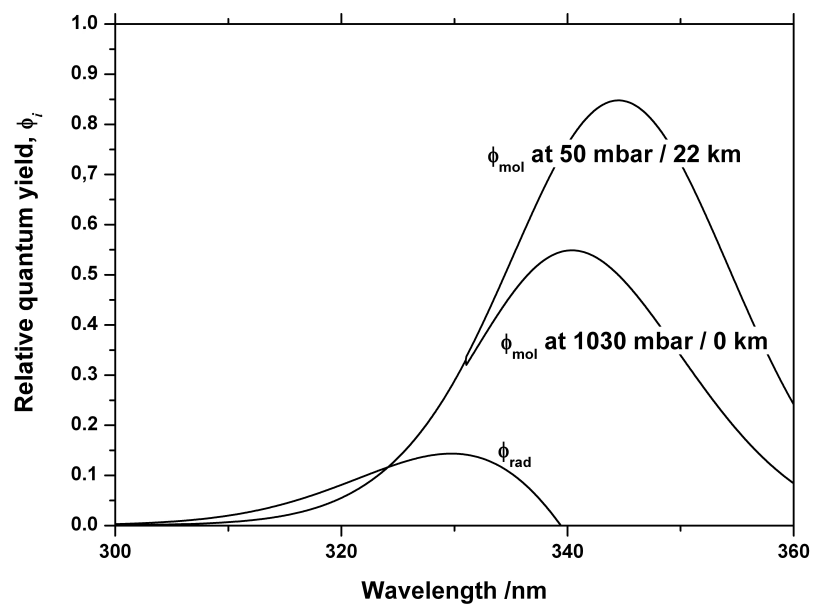

Fig. 4. Quantum yields from JPL (Sander et al., 2006) in the radical channel, and in the molecular channel at two different pressures, scaled by the photolysis lamp spectrum (Fig. 1).

the radical channel, and for the molecular channel at two different pressures, 50 and 1030 mbar.

For the data analysis we use the quantum yields recommended by JPL, since this parameterization includes the pressure dependence. Quantum yields for formaldehyde have also been published by IUPAC (Atkinson et al., 2005; Troe, 2007) and by the group of Orr-Ewing (Gorrotxategi Carbajo et al., 2008). Use of one of the other available quantum yields would change the partitioning between molecular and radical channels slightly. Troe's results (2007) can be convoluted with the lamp spectrum to show that the radical channel contribution may be up to $30 \%$ smaller than we have calculated using the JPL recommendation, whereas the IUPAC recommendation (Atkinson et al., 2005) says that it may be $5 \%$ larger. The most recent experimental study reports radical channel quantum yields that are larger than the mentioned recommendations (Gorrotxategi Carbajo et al., 2008). The uncertainty in the quantum yield clearly introduces an uncertainty in the evaluation of the experimental results of the present work. In contrast to the molecular channel, the radical channel quantum yield is not pressure dependent (Atkinson et al., 2005; Sander et al., 2006). Therefore the radical channel deuterium photolytic kinetic isotope effect is not expected to depend on pressure.

The relative photolysis rate $k_{\mathrm{HCHO}} / k_{\mathrm{HCDO}}$ can be divided into molecular and radical contributions according to Eq. (2) below. Here the subscripts $\mathrm{H}$ and $\mathrm{D}$ distinguish between normal hydrogen $\left({ }^{1} \mathrm{H}\right)$ and deuterium $\left({ }^{2} \mathrm{H}\right)$. Capital letters are used for the rates of production of molecular products, while lower case represents the radical channel.

$\frac{k_{\mathrm{HCHO}}}{k_{\mathrm{HCDO}}}=\frac{k_{H}+k_{h}}{k_{D}+k_{d}}=\frac{k_{H}+c k_{H}}{k_{D}+\frac{c}{r} k_{H}}$

The factor $c=k_{h} / k_{H}$, the ratio between photolysis rates in the radical and molecular channels, is derived for different

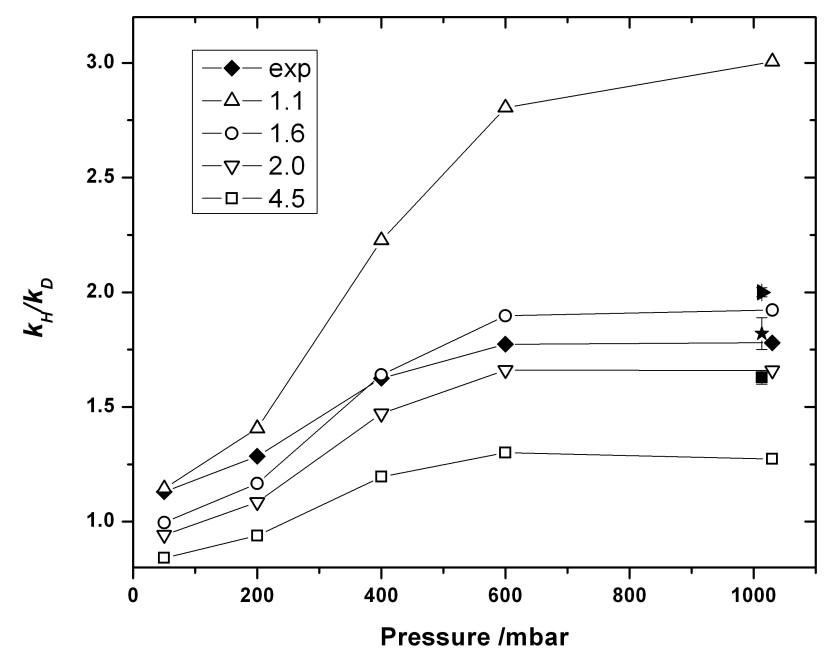

Fig. 5. The filled diamonds are averages of the experimental results for $k_{\mathrm{HCHO}} / k_{\mathrm{HCDO}}$ at different pressures presented in Table 2 and Fig. 3. Open symbols represent derived molecular channel isotope effects, $k_{H} / k_{D}$, when different radical channel corrections have been applied to the experimental data. Previous results for atmospheric pressure measurements of the kinetic isotope effect in the molecular channel $\left(k_{H} / k_{D}\right)$ are shown using a filled triangle (Rhee et al., 2008), a filled star (Feilberg et al., 2007) and a filled square (Röckmann et al., 2009).

pressures using Eq. (1). The factor $r=k_{h} / k_{d}$ is the isotope effect in the radical channel, previously determined by two groups, see Table 1. Defining the factors $c$ and $r$ allows us to look at their effect on the results, as discussed below.

From Eq. (2) we can derive an expression for the isotope effect in the molecular channel:

$\frac{k_{H}}{k_{D}}=\left(\frac{k_{\mathrm{HCDO}}}{k_{\mathrm{HCHO}}}+\frac{c}{k_{\mathrm{HCHO}} / k_{\mathrm{HCDO}}}-\frac{c}{r}\right)^{-1}$

The $k_{\mathrm{HCHO}} / k_{\mathrm{HCDO}}$ ratios are provided by the experiment. The resulting isotope effect for the molecular channel, $k_{H} / k_{D}$, is sensitive to the values of $c$ and $r$. The ratio $c$ varies with pressure since it contains the pressure dependent photolysis rate for the molecular channel. As discussed previously different quantum yields are found in the literature that have a varying ratio between the molecular and radical channels, and thus $c$ will vary depending on the choice of quantum yield. Different available quantum yields give $c$ values that vary by a few percent. In contrast the parameter $r$ has been determined twice, with greatly differing values, as shown in Table 1, and therefore the choice of $r$ introduces a large uncertainty in the present analysis. Figure 5 shows $k_{H} / k_{D}$ ratios where different values for $r$ have been inserted in Eq. (3).

As listed in Table 1 previous determinations of $k_{H} / k_{D}$ at atmospheric pressure are in the range of 1.6 to 2 . The uppermost line in Fig. 5 represents $k_{H} / k_{D}$ in the present experiments when $r=k_{h} / k_{d}$ is set to 1.1 (Feilberg et al., 
2007). This gives an isotope effect in the molecular channel that is about 3 at atmospheric pressure, which clearly disagrees with previous experimental results (Feilberg et al., 2007; Rhee et al., 2008; Röckmann et al., 2009). The other extreme is when $r=4.5$ (Rhee et al., 2008), giving unacceptably low values for $k_{H} / k_{D}$, less than unity at the lower pressures. Based on Troe's work (2007) and the shift in the zero point energy of HCDO relative to HCHO, it is unlikely that $\mathrm{k}_{H} / \mathrm{k}_{D}$ is less than 1 . The two experimentally determined values of $r, 1.1$ and 4.5 , clearly result in $k_{H} / k_{D}$ that are not consistent with field studies, models and experiments. In Fig. $5 k_{H} / k_{D}$ is also presented for $r$ values of 1.6 and 2.0. For $r=1.6$, a value suggested by Röckmann et al. (2009), $k_{H} / k_{D}$ is within the range suggested by previous experiments. When $r=2, k_{H} / k_{D}$ decreases, but is still within the mentioned range.

Given the wide range of $k_{H} / k_{D}$ shown in Fig. 5, especially at the higher pressures where we have other experimental data to compare with, we conclude that the uncertainties in literature data regarding quantum yield and radical channel KIE limit the possibilities for parameterizing the molecular channel KIE based on the present dataset. However we believe that the more important conclusion is that, independent of the value of the radical channel KIE, a significant pressure dependence remains.

\section{Atmospheric implications}

The effect of pressure on the kinetic isotope effect in the photolysis of formaldehyde has been investigated for the first time. A significant pressure dependence, attributed to the molecular channel, is observed.

The fractionation factor for formaldehyde photolysis shows a significant variation with altitude. This has previously been suggested by analysis of field measurements and modeling of $\delta \mathrm{D}\left(\mathrm{H}_{2}\right)$ values in the atmosphere (Mar et al., 2007; Röckmann et al., 2003). In 2001 Gerst and Quay presented a result that could explain deuterium enrichment in molecular hydrogen originating from atmospheric methane. They estimated that the overall fractionation in methane oxidation must be about 1.3 to explain the measured data (Gerst and Quay, 2001). Since then, knowledge of the fractionation factors and branching ratios in the oxidation chain has increased and has been incorporated in modeling of recent field measurements. Rahn et al. (2009) assume stratospheric conditions at $30 \mathrm{~km}$ altitude and report an overall fractionation of 1.33(+0.29/-0.25) (Rahn et al., 2003). Rhee et al. use average stratospheric conditions when deriving the overall fractionation factor from field data; $\alpha_{\mathrm{CH}_{4} \rightarrow \mathrm{H}_{2}}=1.43 \pm 0.06$ (Rhee et al., 2006a). Although several studies indicate altitude dependence in the fractionation, the lack of experimental evidence or estimates of the magnitude of the altitude dependence makes it problematic to incorporate in models. In the present work we identify the pressure dependence of the photolysis of formaldehyde as one cause for the variation in $\alpha$ with altitude. The consequences of this behavior must be investigated using stratospheric models.

As reviewed in the introduction, the atmospheric pressure fractionation results of Rhee et al. (2008), Feilberg et al. (2007), and Röckmann et al. (2009), do not agree. Regarding the Rhee et al. (2008) study a possible source of errors may be interference from the surface including the known difficulty of maintaining a constant pressure of formaldehyde in the gas phase due to adsorption, solvation and the formation of a polymeric solid. Historically, these phenomena have confounded efforts to measure accurate UV and IR cross sections (Gratien et al., 2007). One way to minimize the impact of surface interactions is to perform photolysis experiments in a large chamber with a low surface to volume ratio. The work of Feilberg et al. (2007) and Röckmann et al. (2009) were both performed in large atmospheric chambers under natural sunlight conditions. Also the study by Rhee et al. was done using natural sunlight. In the present study the yield in the molecular channel was enhanced by using a UVA lamp with a maximum at $350 \mathrm{~nm}$. If there is a wavelength dependence in the kinetic isotope effects the results will differ from the natural sunlight studies. Much of the work that has been done, including our analysis here, assumes that $k_{h} / k_{d}$ and $k_{H} / k_{D}$ are independent of wavelength however we know of no experiments to date that support this view. With this in mind it is also important to note that the spectral distribution of sunlight changes with latitude, season and solar zenith angle. If there is a wavelength dependence this would be a possible explanation for the discrepancies in the results in the molecular channel. In addition the temperature dependence of the photolytic isotope effect remains unexplored. We do not have an explanation for why the radical channel isotope effect of 1.1 determined by Feilberg et al. (2007) appears to be unacceptable and we anticipate that future work will improve upon the current studies.

The significant pressure dependence in the isotopic fractionation in the production of molecular hydrogen in formaldehyde photolysis must be further characterized. This probably includes further studies of pressure dependencies in quantum yield and absorption cross sections, as well as better determinations of the radical channel isotope effect. Using sunlight or available UV lamps one must rely on experimental absorption cross sections and quantum yields to be able to estimate the relative contributions from molecular and radical channels. In this work we have analyzed the loss of reactants; an improvement of the experiments would be to also analyze the products. The molecular products $\mathrm{H}_{2}$ and $\mathrm{CO}$ can be analyzed with IRMS (Isotope Ratio Mass Spectrometry) or GC (Gas Chromatography) with a $\mathrm{HgO}$ reduction detector and FTIR, while the radical products are difficult to detect in an accurate way.

In addition to more experimental studies a theoretical investigation would lead to a better understanding of the different timescales of $\mathrm{HCHO}$ and $\mathrm{HCDO}$ photolysis. 
Acknowledgements. The authors thank F. Nicolaisen for help and advice with the reference spectra and T. Röckmann for many useful discussions. HS thanks The Danish Strategical Research Council and the project HYSCENE. EJKN, VFA and MSJ thank the Copenhagen Center for Atmospheric Research, supported by the Danish Natural Science Research Council and the Villum Kann Rasmussen foundation.

Edited by: J. N. Crowley

\section{References}

Atkinson, R., Baulch, D. L., Cox, R. A., Crowley, J. N., Hampson, R. F., Hynes, R. G., Jenkin, M. E., Rossi, M. J., and Troe, J.: Evaluated kinetic and photochemical data for atmospheric chemistry: Volume II - reactions of organic species, Atmos. Chem. Phys. Discuss., 5, 6295-7168, 2005, http://www.atmos-chem-phys-discuss.net/5/6295/2005/.

Bowman, J. M. and Zhang, X.: New insights on reaction dynamics from formaldehyde photodissociation, Physical Chemistry Chemical Physics, 8, 321-332, 2006.

Ehhalt, D. H. and Rohrer, R.: The tropospheric cycle of $\mathrm{H}_{2}$ : a critical review, Tellus, 61B, 500-535, 2009.

Feilberg, K. L., Johnson, M. S., Bacak, A., Röckmann, T., and Nielsen, C. J.: Relative tropospheric photolysis rates of HCHO and HCDO measured at the European Photoreactor Facility, Journal of Physical Chemistry A, 111, 9034-9046, 2007.

Feilberg, K.L., D’Anna, B., Johnson, M. S., Nielsen, C. J.: Relative tropospheric photolysis rates of $\mathrm{HCHO},(\mathrm{HCHO})-\mathrm{C}-13$, (HCHO)-O-18, and DCDO measured at the european photoreactor facility, J. Phys. Chem. A, 109, 8314, doi:10.1021/jp0513723, 2005.

Forster, P., Ramaswamy, P., Artaxo, P., Berntsen, T., Betts, R., Fahey, D. W., Haywood, J., Lean, J., Lowe, D. C., Myhre, G., Nganga, J., Prinn, R., Raga, G., Schulz, M., and Van Dorland, R.: Changes in Atmospheric Constituents and in Radiative Forcing, in: Climate Change 2007: The Physical Science Basis. Contribution of Working Group I to the Fourth Assessment Report of the Intergovernmental Panel on Climate Change, edited by: Solomon, S. e. a., Cambridge University Press, UK and USA, 2007.

Gerst, S. and Quay, P.: Deuterium component of the global molecular hydrogen cycle, J. Geophys. Res.-Atmos., 106, 5021-5031, 2001.

Gorrotxategi Carbajo, P., Smith, S. C., Holloway, A.-L., Smith, C. A., Pope, F. D., Shallcross, D. E., and Orr-Ewing, A. J.: Ultraviolet photolysis of $\mathrm{HCHO}$ : Absolute $\mathrm{HCO}$ quantum yields by direct detection of the HCO radical product, J. Phys. Chem., 112, 12437-12448, 2008.

Gratien, A., Nilsson, E., Bache-Andreassen, L., Doussin, J.-F., Johnson, M. S., Nielsen, C. J., Stenstrøm, Y., and PicquetVarrault, B.: UV and IR absorption cross-sections and relative photolysis rates of HCHO, HCDO and DCDO, J. Phys. Chem. A, 111, 11506-11513, 2007.

Griffith, D. W. T.: Synthetic calibration and quantitative analysis of gas-phase FT-IR spectra, Appl. Spectrosc., 50, 59-70, 1996.

Ianni, J. C.: Kintecus V3.962 for windows, www.kintecus.com, 2009.
Jørgensen, S., Grage, M. M. L, Nyman, G., and Johnson, M. S.: Isotope effects in photodissociation: Chemical reaction dynamics and implications for atmospheres, Adv. Quant. Chem., 55, 9037-9046, 2008

Mar, K. A., McCarthy, M. C., Connell, P., and Boering, K. A.: Modeling the photochemical origins of the extreme deuterium enrichment in stratospheric $\mathrm{H}_{2}$, J. Geophys. Res.-Atmos., 112, D19302 doi:10.1029/2006JD007403, 2007.

Nilsson, E., Johnson, M. S., Taketani, F., Matsumi, Y., Hurley, M. D., and Wallington, T. J.: Atmospheric deuterium fractionation: $\mathrm{HCHO}$ and $\mathrm{HCDO}$ yields in the $\mathrm{CH}_{2} \mathrm{DO}+\mathrm{O}_{2}$ reaction, Atmos. Chem. Phys., 7, 5873-5881, 2007, http://www.atmos-chem-phys.net/7/5873/2007/.

Nilsson, E. J. K., Eskebjerg, C., and Johnson, M. S.: A photochemical reactor for studies of atmospheric chemistry, Atmos. Environ., 43(18), 3029-3033, 2009.

Novelli, P. C., Lang, P. M., Masarie, K. A., Hurst, D. F., Myers, R., and Elkins, J. W.: Molecular hydrogen in the troposphere: Global distribution and budget, J. Geophys. Res., 104, $30427-$ 30444, 1999.

Pieterse, G., Krol, M. C., and Röckmann, T.: A consistent molecular hydrogen isotope chemistry scheme based on an independent bond approximation, Atmos. Chem. Phys., 9, 8503-8529, 2009, http://www.atmos-chem-phys.net/9/8503/2009/.

Rahn, T., Eiler, J. M., Boering, K. A., Wennberg, P. O., McCarthy, M. C., Tyler, S., Schauffler, S., Donnelly, S., and Atlas, E.: Extreme deuterium enrichment in stratospheric hydrogen and the global atmospheric budget of $\mathrm{H}_{2}$, Nature, 424, 918-921, 2003.

Rhee, T. S., Brenninkmeijer, C. A. M., Brass, M., and Bruhl, C.: Isotopic composition of $\mathrm{H}-2$ from $\mathrm{CH} 4$ oxidation in the stratosphere and the troposphere, J. Geophys. Res.-Atmos., 111, D23303, doi:10.1029/2005JD006760, 2006a.

Rhee, T. S., Brenninkmeijer, C. A. M., and Rockmann, T.: The overwhelming role of soils in the global atmospheric hydrogen cycle, Atmos. Chem. Phys., 6, 1611-1625, 2006b, http://www.atmos-chem-phys.net/6/1611/2006/.

Rhee, T. S., Breninkmeijer, C. A. M., and Röckmann, T: Hydrogen isotope fractionation in the photolysis of formaldehyde, Atmos. Chem. Phys., 8, 1353-1366, 2008, http://www.atmos-chem-phys.net/8/1353/2008/.

Röckmann, T., Rhee, T. S., and Engel, A.: Heavy hydrogen in the stratosphere, Atmospheric Chemistry and Physics, 3, 2015-2023, 2003.

Rothman, L. S., Jacquemart, D., Barbe, A., Benner, D. C., Birk, M., Brown, L. R., Carleer, M. R., Chackerian, C., Chance, K., Coudert, L. H., Dana, V., Devi, V. M., Flaud, J. M., Gamache, R. R., Goldman, A., Hartmann, J. M., Jucks, K. W., Maki, A. G., Mandin, J. Y., Massie, S. T., Orphal, J., Perrin, A., Rinsland, C. P., Smith, M. A. H., Tennyson, J., Tolchenov, R. N., Toth, R. A., Vander Auwera, J., Varanasi, P., and Wagner, G.: The HITRAN 2004 molecular spectroscopic database, J. Quant. Spectrosc. Radiat. T., 96, 139-204, 2005.

Sander, S. P., Golden, D. M., Kurylo, M. J., Moortgat, G. K., Wine, P. H., Ravishankara, A. R., Kolb, C. E., Molina, M. J., FinlaysonPitts, B. J., Huie, R. E., and Orkin, V. L.: Chemical Kinetics and Photochemical Data for Use in Atmospheric Studies. Evaluation Number 15, National Aeronautics and Space Administration, Jet Propulsion Laboratory, California Institute of Technology, Pasadena, California, USA, JPL Publication 06-2, 2006. 
Schmidt, H.-L., Werner, R. A., Eisenreich, W.: Systematics of ${ }^{2} \mathrm{H}$ patterns in natural compounds and its importance for the elucidation of biosynthetic pathways, Phytochem. Rev. 2, 61-85, 2003.

Townsend, D., Lahankar, S. A., Lee, S. K., Chambreau, S. D., Suits, A. G., Zhang, X., Rheinecker, J., Harding, L. B., and Bowman, J. M.: The roaming atom: Straying from the reaction path in formaldehyde decomposition, Science, 306, 1158-1161, 2004.
Troe, J.: Analysis of quantum yields for the photolysis of formaldehyde at $\lambda>310 \mathrm{~nm}$, Journal of Physical Chemistry A, 111, 38683874, 2007. 